\title{
Sciendo
}

\section{OVERCOMING BACTERIAL RESISTANCE TO ANTIBIOTICS: THE URGENT NEED - A REVIEW}

\author{
Magdalena Stachelek ${ }^{1 \#}$, Magdalena Zalewska ${ }^{1,2 \#}$, Ewelina Kawecka-Grochocka ${ }^{3}$, Tomasz Sakowski ${ }^{1}$, \\ Emilia Bagnicka ${ }^{1 *}$
}

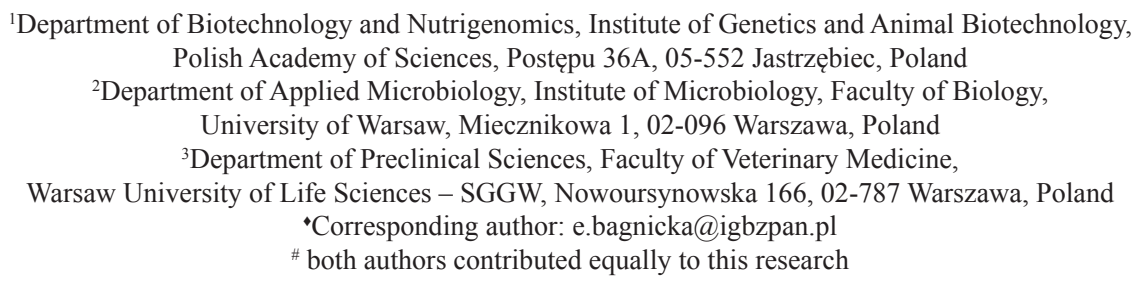

\begin{abstract}
The discovery of antibiotics is considered one of the most crucial breakthroughs in medicine and veterinary science in the 20th century. From the very beginning, this type of drug was used as a 'miraculous cure' for every type of infection. In addition to their therapeutic uses, antibiotics were also used for disease prevention and growth promotion in livestock. Though this application was banned in the European Union in 2006, antibiotics are still used in this way in countries all over the world. The unlimited and unregulated use of antibiotics has increased the speed of antibiotic resistance's spread in different types of organisms. This phenomenon requires searching for new strategies to deal with hard-to-treat infections. The antimicrobial activity of some plant derivatives and animal products has been known since ancient times. At the beginning of this century, even more substances, such as antimicrobial peptides, were considered very promising candidates for becoming new alternatives to commonly used antimicrobials. However, many preclinical and clinical trials ended without positive results. A variety of strategies to fight microbes exist, but we are a long way from approving them as therapies. This review begins with the discovery of antibiotics, covers the modes of action of select antimicrobials, and ends with a literature review of the newest potential alternative approaches to overcoming the drug resistance phenomenon.
\end{abstract}

Key words: antibiotic, resistance, bacteria, superbug

The word 'antibiotic' is derived from Greek: with "anti” meaning "against" and "bioticos" meaning "related to life". This term was introduced into modern medi- 
cine in 1947 by the biochemist/microbiologist Selman Waksman (1888-1973). He defined antibiotics as "substances produced by microorganisms and demonstrating inhibition of other microorganisms' growth, or even killing them" (Waksman, 1947). Now, the term "antibiotic" has a broader meaning - it describes any substances with antimicrobial activity, regardless of origin (natural, semi-synthetic, or synthetic) (Mohr, 2016). Thus, antibiotics are substances that show bacteriostatic (i.e., growth inhibitory) or bactericidal activity at relatively low concentrations. These substances affect different mechanisms crucial for bacterial cell function, e.g., cell growth and division, as well as metabolic pathways. Furthermore, antibiotics can originate from very diverse substances: they can be produced by natural organisms, mainly microbes such as fungi or bacteria, but also molds, lichens, algae, plants, and animals, or they can be semi-synthetic or synthetic. Antibiotics as chemotherapeuticals are commonly used in medicine for treating infections caused by different species of bacteria, fungi, or protozoa. Some can also be used as anticancer drugs or as an immunosuppressant. Despite their primary purpose in treatment, these types of drugs have been also widely used in animal agriculture (Davies and Davies, 2010).

The aim of this study was to outline the history of antibiotic usage over the years, analyze the modes of antibiotic action, and discuss new strategies for overcoming bacterial resistance to antibiotic drugs.

\section{Historical background}

Humans, for centuries, have been using various types of biological materials containing microorganisms to treat different diseases. Hippocrates recommended using drinking water containing powdered yeast to combat infectious diseases (Wolf and Lewis, 2019) or garlic to treat vaginal infections (Jouanna, 2012). The ancient Greeks, more than 2,500 years ago, also treated foot infections by wearing sandals covered in mold, and for furuncles, they used moldy cheese. In Mayan medicine, one of the most valuable drugs against skin diseases and food poisoning was a mold growing on green grain named 'cuxum' (Wrigley et al., 2000). There is a very wellknown fact of beneficial microorganism use as the treatment of infected soft tissue and skin wounds with moldy bread or bread mixed with a spider web. Moreover, tetracycline was found in the human skeletal remains of Sudanese Nubian residents dating back to 350-550 C.E. while in that time, tetracycline dispersion in bones was possible only after consuming tetracycline-containing food products (Aminov, 2010). Its prints were also found in human bone samples (in Egyptian territory) which were dated to the late Roman Times (Cook et al., 2014). Despite the fact that John Tyndall of London and William Roberts of Manchester were the first to describe Penicillium in 1875, it was Louis Pasteur and J. F. Joubert who officially described the antagonistic interaction between different bacterial species in 1877 . Though Tyndall's observations were very detailed and demonstrated that antagonism was occurring between Penicillium and bacteria, today it is clear that he did not consider antibiosis as the reason, which is why he is not credited with discovering penicillin (Wainwright, 1985). Pasteur's and Joubert's observations were more specific and pertained to the antagonism between the bacilli of anthrax and putrefaction bacteria (Kon and Rai, 2016). As Bentley (1997) stated, “Antagonisms between mi- 
croorganisms were termed 'antibiosis' in 1890, eventually leading to the present-day usage of antibiotic."

Subsequently, in 1897, the French military doctor Ernest Duchesne (1874-1912) described the inhibition of pathogenic microorganism growth by molds in his doctoral dissertation "Contribution à l'étude de la concurrence vitale chez les microorganismes: antagonisme entre les moisissures et les microbes" (Contribution to the study of the competition between microorganisms: antagonism between the molds and microbes). He first observed that Arab grooms, hired to work in the stable of the military hospital, would keep their saddles in dark, wet places to cover them with mold, which further helped to treat the horses' skin wounds (mainly abrasions) caused by the saddle while riding. Therefore, Duchesne investigated the interaction between Escherichia coli and Penicillium glaucum, showing that E. coli could be eliminated from culture medium containing both bacteria and mold. Furthermore, he also showed that animals infected with a lethal dose of typhoid fever defeated the disease only when they had been previously vaccinated with $P$. glaucum. Duchesne then prepared a solution containing both the mold (P. glaucum) and bacteria (E. coli) and injected this mixture into guinea pigs. Not only did the animals survive, but they also were immune to the bacteria. Notwithstanding, these results were not confirmed in further tests conducted by Scottish bacteriologist Alexander Fleming (1881-1955), who showed a lack of interaction between Penicillium notatum and abdominal typhoid germs. However, due to his age (23 years old), Duchesne was not recognized by the medical establishment. Unfortunately, Duchesne had to stop his study because his military supervisors told him to finish all his research. Duchesne died in 1912 at the age of 37. In 1949, five years after Fleming was awarded the Nobel Prize, Duchesne's research contributions were formally acknowledged: the French Académie Nationale de Médecine recognized his work as the precursor of antibiotic therapy (Duckett, 1999; Pouillard, 2002; Shama, 2016).

The next step in the treatment of infectious diseases was a breakthrough in syphilis therapy. In 1910, Dr. Paul Ehrlich, together with Drs. Alfred Bertheim and Sahachiro Hata, introduced the chemotherapeutic drug Salvarsan, which has also been considered the very beginning of the antibiotic era. Though it cured many people, Salvarsan had many side effects, and further improvements needed to be made (Kubicki, 2013).

It is common knowledge that the first antibiotic (penicillin) was discovered by accident by Alexander Fleming in September 1928. Professor Fleming, in his research on a vaccine against typhus, noticed the inhibiting effect of $P$. notatum on bacterial colonies. The active compound remained unknown, but its presence and activity were confirmed (it demonstrated high activity, even in small doses) (Fleming, 1929; Bennett and Chung, 2001). Fleming also developed a new method of investigating the presence of antimicrobials. Pure penicillin was first isolated in 1938 by H. W. Florey (1898-1968) and E. B. Chain (1906-1979) from Oxford University, who conducted the first trials on animals and humans (Arseculeratne and Arseculeratne, 2017).

The identification of antibiotics is considered one of the biggest discoveries of the 20th century. The antibiotic era flourished in 1942, when Alexander Fleming saved 
a man dying from meningitis by giving him penicillin first intravenously, then directly via cerebral-spinal fluid. By the end of World War II, penicillin was used for soldiers' wound treatment (Mohr, 2016). Before the introduction of penicillin, almost $80 \%$ of people infected with Staphylococcus aureus died, and pneumonia also led to many deaths. After 1941, many infections that were once lethal became fully curable, and severe, life-threatening diseases became easier to treat (Landecker, 2016). Identifying the first antibiotic was the impetus for further research. However, shortly after the initial enthusiasm, doubts arose - it appears that microorganisms are able to develop resistance mechanisms very quickly once an antibiotic is widely used. These resistance mechanisms can be directed against particular classes of antibiotics, or they can act in a non-selective manner (see the "Drug resistance" section for more details). Key antibiotic introductions, as well as the date by which bacteria became resistant to them, are presented in Table 1.

Table 1. Dates of antibiotic introduction and the emergence of resistance to them

\begin{tabular}{|c|c|c|}
\hline Antibiotic & Introduction date & Date of identified antibiotic resistance \\
\hline Penicillin & 1943 & 1965 - penicillin-resistant Pneumococcus spp. \\
\hline Tetracycline & 1950 & 1959 - tetracycline-resistant Shigella spp. \\
\hline Erythromycin & 1953 & 1968 - erythromycin-resistant Streptococcus spp. \\
\hline Methicillin & 1960 & 1962 - methicillin-resistant Staphylococcus spp. \\
\hline Gentamycin & 1967 & 1979 - gentamycin-resistant Enterococcus spp. \\
\hline Vancomycin & 1972 & $\begin{array}{l}1988 \text { - vancomycin-resistant Enterococcus spp. } \\
2002 \text { - vancomycin-resistant Staphylococcus spp. }\end{array}$ \\
\hline Ceftazidime & 1985 & 1987 - ceftazidime-resistant Enterobacteriaceae \\
\hline Imipenem & 1985 & 1998 - imipenem-resistant Enterobacteriaceae \\
\hline Levofloxacin & 1996 & $\begin{array}{l}1996 \text { - levofloxacin-resistant Pneumococcus spp. } \\
2000 \text { - extensively drug-resistant tuberculosis }\end{array}$ \\
\hline Linezolid & 2000 & 2001 - linezolid-resistant Staphylococcus spp. \\
\hline Daptomycin & 2003 & $\begin{array}{l}\text { not reported } \\
2004 \text { - pan-drug resistant Pseudomonas spp. and Aci- } \\
\text { netobacter spp. }\end{array}$ \\
\hline Ceftaroline & 2010 & 2011 - ceftaroline-resistant Staphylococcus spp. \\
\hline
\end{tabular}

Based on Davies and Davies, 2010 and Woc-Colburn and Francisco, 2020.

\section{Antibiotics' mode of action}

Nowadays, some of the most commonly used antibiotics are synthetic (e.g., chloramphenicol) and some are semi-synthetic (e.g., ampicillin, cloxacillin, and dicloxacillin); however, some of them are of natural origin, e.g., benzylpenicillin, also known as Penicillin $\mathrm{G}$ and phenoxymethylpenicillin, also known as Penicillin V (Ball et al., 1978). 
Table 2. Antibiotic classes by exact mode of action

\begin{tabular}{c|c|c}
\hline The general mode of action & Antimicrobial family & Examples \\
\hline 1 & 2 & 3 \\
\hline
\end{tabular}

Cell wall synthesis inhibitors (peptidoglycan synthesis inhibitors)

Cytoplasmic membrane function inhibitors

Protein synthesis inhibitors

rRNA 30S

subunit inhibitors
Beta-lactams - bind to PBPs (penicillin-binding proteins), which prevents peptidoglycan from forming penicillins (oxacillin, ampicillin, methicillin), cephalosporins (cefotaxime, ceftazidime), monobactams (aztreonam), and carbapenems (imipenem, meropenem)

Glycopeptides - bind to the side chains of vancomycin, peptidoglycan precursors, which prevents the teicoplanin binding of D-alanyl D-alanine to PBPs

Polymyxins - are cationic, surface-active polymixin B, colistin agents that displace $\mathrm{Mg}^{2+}$ or $\mathrm{Ca}^{2+}$ and disrupt the structure of cell membrane phospholipids and increase cell permeability

Aminoglycosides - interact with the $30 \mathrm{~S}$ subunit near the A site, resulting in the mis- kanamycin reading and premature termination of mRNA translation

Tetracyclines - interact with the 30S rRNA tetracycline, ribosomal subunit, preventing the binding of oxytetracycline, tRNA to the A site chlortetracycline

rRNA 50S subunit inhibitors
Macrolides - target the peptidyl transferase center of the 23S rRNA of the 50S subunit of the

clarithromycin, erythromycin ribosome (to the $\mathrm{P}$ site), resulting in premature detachment of an incomplete peptide chain (i.e., they inhibit the translocation process)

Streptogramins - target the peptidyl transfer- quinupristin, ase center of the $23 \mathrm{~S}$ rRNA of the $50 \mathrm{~S}$ subunit dalfopristin of the ribosome (to the $\mathrm{P}$ site), resulting in premature detachment of an incomplete peptide chain (streptogramins belonging to group A - macrolactons - inhibit peptide elongation; streptogramins belonging to group $\mathrm{B}$ - cyclic hexapeptides - inhibit peptide bond creation, resulting in premature detachment of an incomplete peptide chain)

Lincosamides - target the peptidyl transferase clindamycin, center of the 23S rRNA of the 50S subunit of lincomycin the ribosome (which inhibits the attachment of aminoacyl-tRNA to the ribosome A site)

Chloramphenicol - interacts with the peptidyl chloramphenicol transferase cavity of the $23 \mathrm{~S}$ rRNA of the $50 \mathrm{~S}$ rRNA subunit, thus preventing the binding of tRNA to the A site of the ribosome

Oxazolidinones - act on protein synthesis at linezolid, posizolid two levels: by binding to $23 \mathrm{~S}$ rRNA of the $50 \mathrm{~S}$ ribosome subunit and by interacting with peptidyl-tRNA 
Table 2 - contd.

\begin{tabular}{|c|c|c|}
\hline 1 & 2 & 3 \\
\hline DNA replication inhibitors & $\begin{array}{l}\text { Quinolones - inhibit bacterial DNA gyrase, } \\
\text { which nicks the double-stranded DNA, in- } \\
\text { troduces negative supercoils, then releases } \\
\text { nicked ends }\end{array}$ & $\begin{array}{l}\text { ciprofloxacin, levofloxa- } \\
\text { cin, nalidixic acid }\end{array}$ \\
\hline RNA synthesis inhibitors & $\begin{array}{l}\text { Rifampicin - binds to the } \beta \text { subunit of the } \\
\text { DNA-dependent RNA polymerase (which } \\
\text { inhibits mRNA synthesis) }\end{array}$ & rifampicin \\
\hline $\begin{array}{l}\text { Folic acid metabolism inhibi- } \\
\text { tors }\end{array}$ & $\begin{array}{l}\text { Sulfonamides - inhibit dihydropteroate syn- } \\
\text { thase }\end{array}$ & $\begin{array}{l}\text { sulfadiazine, sulfa- } \\
\text { methoxazole }\end{array}$ \\
\hline $\begin{array}{l}\text { (Antibiotics belonging to } \\
\text { this group are competitive } \\
\text { inhibitors of the enzyme dihy- } \\
\text { dropteroate synthetase. This } \\
\text { enzyme catalyzes the conver- } \\
\text { sion of para-aminobenzoate } \\
\text { to dihydropteroate, which is } \\
\text { a crucial level in the folate } \\
\text { synthesis pathway. Folate is } \\
\text { essential for the bacterial cell } \\
\text { to synthesize nucleic acids, } \\
\text { which in turn builds DNA and } \\
\text { RNA) }\end{array}$ & $\begin{array}{l}\text { Trimethoprim - inhibits dihydrofolate reduc- } \\
\text { tase }\end{array}$ & trimethoprim \\
\hline
\end{tabular}

Based on Barna and Williams, 1984; Chopra and Roberts, 2001; Davies and Davies, 2010; Dowling, 2013 a; Kapoor et al., 2017; Schwarz et al., 2016.

The structure and modes of action of these substances are, in most cases, wellknown; however, different antibiotics work by different modes of action, as listed in Table 2 and outlined in detail below:

1. Antibiotics may interact with murein synthesis pathways. The activity of all $\beta$-lactam antibiotics, i.e., penicillin derivatives, cephalosporins, monobactams, and carbapenems, is based on interrupting bacterial cell wall formation by interfering in the last stage of peptidoglycan synthesis: they inhibit the activity of transpeptidase and other peptidoglycan-active enzymes called penicillin-binding proteins (PBPs), which catalyze cross-linkage of the glycopeptide polymer units that form the cell wall; only cells in growth phase are sensitive to such antibiotic action. Glycopeptides, e.g., vancomycin, or teicoplanin, are large molecules that also inhibit cell wall synthesis by interrupting peptidoglycan polymerization and subsequently causing the accumulation of peptidoglycan precursors inside the cell. Cell breakage occurs as an effect of the lower durability of the bacterial cell wall. However, it is also important to note that the massive bacterial cell wall degradation caused by these antibiotics can lead to an uncontrolled release of bacterial toxins (i.e., the Jarisch-Herxheimer reaction), which can be responsible for the deterioration of health rather than its improvement (Prescott, 2013).

2. Other antibiotics interacting with the bacterial cell membrane are polymyxins, e.g., polymyxin B, colistin, which are cationic antimicrobial peptides that disrupt 
the integrity of the cell membrane. They disorganize the outer membrane of Gramnegative bacteria by binding to lipopolysaccharides (Dowling, 2013 a).

Antibiotics can also interact with bacterial metabolic pathways. Lincosamides (e.g., clindamycin) inhibit bacterial protein synthesis by binding to the $50 \mathrm{~S}$ ribosomal subunit. The detailed mode of action has been not fully elucidated, but most probably, lincosamides inhibit the binding of aminoacyl-tRNA to subunit A of the ribosome. The ribosomal binding sites for this antimicrobial are closely related to (or the same as) those of macrolides (e.g., erythromycin) or chloramphenicol (Giguère and Dowling, 2013). Aminoglycosides (e.g., amikacin, gentamicin) have a slightly different mode of action: they also bind to the ribosome, but to the $30 \mathrm{~S}$ subunit of this molecule, causing the genetic code to be misread. Protein synthesis is thereby disrupted, resulting in serious issues for the target cell, e.g., cell membrane permeabilization causing an increased intake of the antibiotic and thus cell death (Dowling, 2013 a). Antibiotics may also inhibit deoxyribonucleic acid or ribonucleic acid synthesis pathways, such as in the case of rifamycins, which inhibit DNA-dependent RNA polymerase in bacteria, or of nalidixic acid, which affects the activity of bacterial topoisomerases (Dowling, $2013 \mathrm{~b}$ ).

The mechanisms of action described above should act selectively, i.e., only on the pathogen and not on the host's cells, because the structure and metabolic pathways of bacteria are different from those of humans. Human cells and nucleic acids should remain unaffected when in contact with antimicrobial agents. However, many side effects are related to mitochondria because their structure is very similar to that of a bacterial cell. Ribosomes in mitochondria can be inhibited by antibiotics targeting bacterial ribosomes (Duewelhenke et al., 2007).

Antibiotics can be divided into two groups: 1) those with a narrow spectrum of activity, where activity is limited to a small number of species or group of microorganisms and 2) those with a broad spectrum of activity, where there is activity against a whole genus or family. Different strains of bacteria can differ from each other with regard to their susceptibility to an antibiotic. Thus, microorganisms can be either: 1) sensitive (in doses easily attainable in blood serum) or 2) resistant to an antibiotic. It is essential to understand that some specific conditions, e.g., sub-lethal doses of an antibiotic present in the natural environment (Cirz et al., 2005), can help transform a strain from one that is sensitive to one that is resistant.

Despite the many mechanisms represented by the different classes of antibiotics, microorganisms can develop efficient mechanisms to avoid the destructive action of those substances. As soon as a new antibiotic is introduced, pathogens evolve new, previously undescribed mechanisms to overcome its activity.

\section{Drug resistance}

The excessive, i.e., not necessarily required, use of antibiotics has led to the current situation of commonly used antibiotics being no longer effective. Drug resistance began in the middle of the 20th century as a result of antibiotics' mass production and overuse. In 2012 alone, approximately 3,400 tons of antibiotics were used to treat people, whereas in the animal industry, 7,982 tons were used (some for disease 
treatment, but most for prophylaxis, metaphylaxis, and growth stimulation) (2014). Drug resistance occurs when microbes develop efficient mechanisms to evade the drugs' mode of action, thus becoming insensitive to them (Landecker, 2016). Resistance can develop via horizontal gene transfer when a microorganism obtains a set of genes; by conjugation, when gene transfer occurs via direct contact between two bacteria; by transduction (gene transfer via bacteriophages); by transformation, which means the uptake of naked DNA from the environment and its incorporation into bacterial DNA (Holmes et al., 2016); or via vertical transfer, i.e., when genes passed down through generations. This particular set of genes can be transferred as a working gene cassette located on mobile genetic elements such as plasmids, or it can be created de novo as a result of spontaneous mutations (Martínez et al., 2007). When microorganisms are exposed to an antibiotic over a long period of time, this can create an environmental niche in which sensitive bacteria are killed and only the resistant strains survive. Furthermore, exposure to antimicrobials triggers SOS response pathways in bacteria. These pathways are associated with error-prone polymerase expression, which generates a higher level of spontaneous mutations to overcome adverse environmental conditions (Singer et al., 2016). Excessive use of inadequate doses of a drug, i.e., too low a concentration or too short an administration time, promotes the survival of well-adapted microorganisms (Andam et al., 2011; von Wintersdorff et al., 2016). After obtaining the resistance gene, bacteria can start producing enzymes that protect their cells from the destructive action of antibiotics, e.g., the newly obtained genes could change the metabolic pathways or code enzymes that deactivate the antibiotic (Peacock and Paterson, 2015). The differences between sensitive and insensitive strains involve: 1) changes in the molecular targets of the drugs, 2) the production of the enzymes responsible for drug inactivation, or 3) the modification of drug intake and drug removal systems (Davies and Davies, 2010). In general, drug resistance mechanisms can be divided into several groups, including those that: 1) prevent antimicrobial uptake; 2) modify a targeted molecule in the bacterial cell; 3 ) inactivate the antibiotic by modifying the molecule into its non-active form; 4) create an enzymatic pathway that is an alternative to the pathway disturbed by the antimicrobial; 5) increase the targeted enzyme concentration; and 6) increase the concentration of the antagonists of the inhibitor. Reaching a therapeutic concentration of an antimicrobial inside the cell may be prevented in two general ways: by decreasing uptake, e.g., reducing the number of porin channels or creating a thicker peptidoglycan layer, or by increasing the efflux of an antibiotic from the cell, e.g., increasing the efficiency of the efflux pump activity. Most of the efflux pumps are multidrug transporters, which can pump out a wide range of antimicrobials from the cell. Modifying a targeted molecule depends on the antibiotic's modes of action. For example, altering the $30 \mathrm{~S}$ and $50 \mathrm{~S}$ ribosome subunit, such as in macrolides, chloramphenicol, or tetracyclines, prevents protein synthesis; modifying PBPs leads to the reduced affinity of $\beta$-lactams to this protein; mutating DNA gyrase or topoisomerase prevents quinolone sensitivity; and mutating RNA polymerase mutations confers resistance to rifampicin. Antibiotic can be inactivated by the action of enzymes. $\beta$-lactams are inactivated by $\beta$-lactamases, which hydrolyse almost all $\beta$-lactams with ester bonds, e.g., penicillinase or extended-spectrum $\beta$-lactamases. 
Phosphoryl-transferases, nucleotidyl-transferases, and adenylyl-transferases can inactivate aminoglycosides. Chloramphenicol-acetyl-transferases are, in turn, related to chloramphenicol resistance (Frieri et al., 2017; Kapoor et al., 2017; Peterson and Kaur, 2018).

Moreover, biofilm formation also contributes to drug resistance. Biofilm has been described as a structured bacterial community, either homogenous or heterogenous, that is able to produce extracellular polymeric matrix to adhere itself to different types of surfaces (Costerton et al., 1987). Bacteria, in most cases, do not exist independently, but persist in metabolically integrated and spatially organized communities. Living in organized communities provides security against a fluctuating and harsh environment (Satpathy et al., 2016). Many bacterial species are well-known for their biofilm-producing ability, e.g., Pseudomonas aeruginosa, Gram-positive cocci affecting contact lenses, Candida spp. affecting dentures, enteric Gram-negative species on endotracheal tubes, E. coli, and Klebsiella pneumoniae affecting urinary catheters, Enterococcus faecalis, Proteus mirabilis, coagulase-negative staphylococci, and $S$. aureus forming a biofilm on a central venous catheter or a mechanical heart valve, coagulase-negative staphylococci, $S$. aureus, and Enterococcus spp. on voice prostheses (Dufour et al., 2010). Twenty years ago, it was estimated that approximately $65 \%$ of all bacterial infections were associated with bacterial biofilm formation (Lewis, 2001). Nowadays, 65\% of all microbial and $80 \%$ of all chronic infections are associated with biofilm formation (Jamal et al., 2018). It has been shown that the ability of fungi and bacteria to form biofilms is highly correlated with antibiotic resistance (Desai et al., 2014; Kouidhi et al., 2015).

Drug resistance of different bacterial species to commonly used antibiotics has recently become one of the most serious concerns in public health. Some bacterial species become resistant much faster than others, e.g., Staphylococcus spp. and $P$. aeruginosa develop drug resistance very easily, while Neisseria gonorrhoeae and some streptococci gain resistance more slowly. Moreover, some antibiotics can develop cross-resistance - meaning that resistance to one drug is related to resistance to a whole group of drugs, e.g., resistance to oxacillin is synonymous to resistance to methicillin. In 1939, in The Lancet, MacLean, Rogers, and Fleming described their observation of a Streptococcus pyogenes strain resistant to sulfonamides in the case of a patient treated with sulfapyridine. Penicillin-resistant $S$. aureus was detected in hospitals right after the introduction of this antibiotic. Furthermore, streptomycinresistant Mycobacterium tuberculosis was identified soon after the discovery of this antibiotic (Levy and Marshall, 2004). As mentioned above, antibiotics have been present in our environment for centuries because they are the products of microbial metabolism naturally freed to the surroundings in small concentrations. It is the large, industrial-scale production and widespread use of antibiotics that have created much larger amounts of these substances in various areas of human lives. Over the years, we have observed a growing number of resistant strains, which are probably related to the growing number of antibiotics used therapeutically in both humans and animals, as well as preventively in agriculture (Cully, 2014).

After 1959, an abnormality began to be observed: patients were resistant to multiple antibiotics without being exposed to them. This observation prompted further 
examination into the causes of resistance development. Data collected by the Centers for Disease Control and Prevention (CDC) in Atlanta (USA) showed that only $0.2 \%$ of pneumococci isolated from hospitalized patients were resistant to penicillin in 1979-1987, while in 1994, 6.6\% of these isolated bacteria were penicillin-resistant. In 1994, in England and Wales, researchers observed only 2\% of severe bacteremia caused by methicillin-resistant $S$. aureus (MRSA); by 1996, severe bacteremia caused by MRSA had increased to 30\% (Hancock, 1997). A report from 2008 noted that in the Antibiotic Resistance Genes Database, there are more than 13,000 resistant genes of almost 400 different types (Liu and Pop, 2009). The newest version of the antibiotic resistance database includes more bioinformatics tools designed for searching/mining the antibiotic resistance-related data from genome sequences using different prediction models, most of which rely on gene ontology. The recently updated version of the abovementioned database - The Comprehensive Antibiotic Resistance Database - CARD - a biological database of antimicrobial resistance genes, proteins, and related phenotypes -contains 4,358 ontology terms; 2,909 reference sequences; 1,318 single nucleotide polymorphisms; 2,663 publications; and 2,943 antimicrobial resistance detection models, which correspond to 85 pathogens; 8,046 chromosomes; 18,337 plasmids; 90,531 whole-genome sequencing assemblies; and 182,532 alleles (Alcock et al., 2019). Other commonly used databases are Pathosystems Resource Integration Center (PATRIC), containing more than 13,500 pathogens' genomes with their antimicrobial-resistant phenotypes (Wattam et al., 2017) and ResFinder (Zankari et al., 2012).

In 1994, the World Health Organization's Scientific Working Group on Antimicrobial Resistance defined drug resistance among microorganisms as a severe health problem in developed and still developing countries. This problem was even discussed by the United Nations (Hancock, 1997). It is very important to understand that the excessive use of antibiotics can lead to the creation of super-bacteria resistant to all known antibiotics (Adegoke et al., 2017). Currently, New Delhi metallo$\beta$-lactamase-1 (NDM-1) is a primary concern. It was discovered and described for the first time in 2009. In 2018, a new variant of NDM was described (NDM-4). It was found in two tourists, one of whom was reported to have been hospitalized in India, where he was infected. This was the first example of an Indian NDM variant being transmitted to Europe. Now that global travel has become so easily available, this case should be a warning about NDM's ability to spread all over the world at a fast pace (Coppo et al., 2014). The high level of mutation occurring among microorganisms is a major problem, as is the much slower rate at which new antibiotics are introduced. According to a CDC report, in the United States, between 1980 and 1984, approximately 20 antibiotics were approved for use, while in the years 2000-2012, only eight drugs were approved (CDC, 2019).

The most pathogenic bacteria causing health problems, especially in immunocompromised patients, are Enterococcus spp., Enterobacter spp., Klebsiella spp., Acinetobacter baumannii, P. aeruginosa, and in particular S. aureus (Moellering, 2011). S. aureus, exhibiting resistance to many antibiotics, including methicillin (MRSA), is a serious concern in institutions related to human health, but also in those not closely related to healthcare. For example, MRSA strains can be also found 
in food-producing animals. Enterococcus species are a normal part of the human commensal microbiota - they cause no problems for a healthy person. However, the bacteria become a serious threat for patients with immunodeficiency, e.g., after organ transplantation or a long hospitalization. This pathogen can be resistant to many antibiotics, but the biggest concern is its insensitivity to aminoglycosides and glycopeptides. Moreover, strains resistant to linezolid have also been reported (Prystowsky et al., 2001). Another concerning species is Streptococcus pneumoniae, responsible for otitis media, pneumonia, and meningitis. This pathogen can be also carried without any symptoms and spread over large areas undetected. E. coli and K. pneumoniae resistant to third-generation cephalosporins are also a great threat, as these bacteria have significant influence on mortality and the length of treatment in hospitals. A. baumannii is a nosocomial pathogen responsible for many hospital outbreaks worldwide. Due to its many resistance genes, infections caused by this bacterium are very hard to treat. P. aeruginosa also causes many nosocomial infections. Multidrug resistance in this species is a significant concern because it leaves only a few options for infection treatment (Cars et al., 2011).

The common and excessive use of antibiotics in veterinary and animal agriculture plays a huge role in the spread of drug resistance. To gain higher production efficiency, antibiotics are used not only in non-targeted therapy but also to prevent infections and promote growth. When an animal is given an antibiotic, resistant bacteria can survive in the organism and increase their population. Moreover, animal feces containing bacteria or antibiotic residues are used as natural fertilizers in fields. These antibiotic remnants or resistant bacteria, as well as antibiotic resistance genes, may, in turn, affect humans or the animals that consume the contaminated food/fodder (CDC, 2019; Chen et al., 2018; Heuer et al., 2011; Wang et al., 2015). In animal agriculture, antibiotics were introduced in the 1950s to promote the growth of chicks, piglets, calves, and lambs, rather than for therapeutic use, which increased companies' profits. After ten years, researchers noticed that the presence of tetracycline in food for chicken was closely related to outbreaks of resistant staphylococci in the environment (Dibner and Richards, 2005).

In 2009 in the Netherlands, poultry (52\%), beef (29\%), pork (29\%), and other kinds of meat samples $(9 \%)$ were examined with a special attention to antibioticresistant Enterobacteriaceae, especially E. coli. The highest rates of resistance were observed for ampicillin (98\%) and amoxicillin with clavulanic acid (80\%). The lowest rate of resistance $(5 \%)$ was in regard to gentamicin. No resistance to ciprofloxacin was found, which means that fluoroquinolones may still show high efficiency in treating $E$. coli infections. E. coli producing $\beta$-lactamase with a broad spectrum of activity (i.e., extended-spectrum $\beta$-lactamase [ESBL]) was isolated from $18 \%$ of poultry meat samples. However, the prevalence may be much higher because $E$. coli producing ESBL was detected in $79.8 \%$ of poultry available to consumers in the Netherlands. Furthermore, genetic analyses have shown that the genes coding ESBL production were identical in the bacteria from poultry meat and from human anus swabs (Bruin et al., 2010; Overdevest et al., 2011).

It is worth mentioning that the animal industries are not the only ones responsible for the antibiotic resistance situation. Environmental pollution with antibiotics is 
also caused by hospitals and pharmaceutical companies. Water polluted with drugs causes not only the depletion of immunity but also mutagenic, carcinogenic, and teratogenic effects (Jones et al., 2005).

According to recent forecasts, by 2050 , incurable bacterial infections will again be the most common cause of death. They may even reach 10 million deaths annually, which means that cancers and cardiovascular diseases will no longer be the most serious threats to human health (Hoffman et al., 2015).

Not even eighty years ago, a discovery was made that resistance to antibiotics is completely natural and had even occurred 30,000 years ago. Thanks to modern laboratory techniques, DNA from that time was analyzed, leading to the identification of the genes responsible for resistance. To make this discovery more credible, further studies on the similarity of those genes to current variants were conducted, and the similarity was confirmed. This finding will facilitate scientists' search for new antibiotics and may help us understand the phenomenon of modern resistance (D’Costa et al., 2011).

\section{Alternative therapies}

In 2000, Roccanova and Rappa proposed antibiotic rotation as a solution to the drug resistance problem. This strategy assumes that discontinuing the use of some antibiotics can cause bacteria to lose their resistance genes to these drugs. Then, the substance can be reintroduced after some time and can once again be effective. Bacteria could again become sensitive to the specific compound as a result of inactivating the resistance mechanism. However, this approach does not take cross-resistance into account. Many contaminants, such as pesticides, biocides, or heavy metals are still present in the surrounding environment. The antibiotic resistance genes are often located in the same gene cassettes. Bacteria would not lose their antibiotic resistance genes because they would still need to be resistant to pesticides or heavy metals.

There is an urgent need to find 'something more' to overcome multidrug resistance, when commonly used antibiotics become insufficient and ineffective. The growing number of resistant pathogens, as well as the risks of a 'superbug' outbreak, require searching for new infection treatments.

The strategies for overcoming bacteria resistance include searching for new antibiotics by synthesizing new chemical compounds or searching for new antibiotics in nature. Relatively new (2003-2007) antimicrobial agents active against Gramnegative bacteria include ertapenem - a carbapenem with high activity against many Enterobacteriaceae (including $\beta$-lactamase producers), doripenem - a carbapenem active against $P$. aeruginosa, and tigecycline - a chemical derivative of minocycline active against many Enterobacteriaceae and significantly active against Grampositive bacteria, including MRSA, vancomycin-resistant Enterococcus spp., and penicillin-resistant pneumococci (Moellering, 2011). Researchers are also trying to identify new potential targets for drugs. Bacterial genome sequencing and molecular biology and genetic engineering tools have created an opportunity to identify new potential targets in the pathogen cell (Cars et al., 2011).

Alternative approaches suggested for overcoming the drug resistance phenomenon include natural substances with antibacterial activity derived from the following: 
- Bacteria, e.g., bacteriocins. Bacteriocins are small proteins or peptides synthesized on ribosomes produced by the bacteria that compete or fight with other microorganisms (mainly closely related species) (Cotter et al., 2005). Bacteriocins are produced in the late log growth phase and at the beginning of the stationary phase, unlike antibiotics, which are a product of secondary metabolism. These peptides and proteins differ in terms of size, thermostability, mode of action, range of activity, and/or secretion mode. Moreover, their spectrum of activity can be very narrow or very broad. Bacteriocins act only on the target bacterial species (and sometimes on closely related species), thus the peptides are not toxic to human cells (and there is a low risk of side effects). Some are already food-safe grade and are used in the food industry, e.g., nisin A, and some have been present in normal human diets for centuries, as they are mainly produced by lactic acid bacteria (Nishie et al., 2012). Some others may be produced by harmful pathogens to take over the environment inhabited by other microorganisms (Zalewska et al., 2018). The main direction in research conducted on potential bacteriocin applications in veterinary science is in the treatment of dairy cow mastitis. The US Food and Drug Administration has approved two bacteriocin-containing formulations: Wipe Out ${ }^{\circledR}$ dairy wipes, a nisin-based udder disinfectant, and Mast Out ${ }^{\circledR}$, an intramammary infusion product containing nisin. Moreover, Lacticin 3147, a lantibiotic produced by Lactococcus lactis DPC3147, has been tested for dry cow therapy in teat seal formulations (Crispie et al., 2004, 2005). The high efficacy of teat dip containing bacteriocins has also been confirmed in studies conducted by Klostermann et al. (2010), who observed that a 10-minute treatment with a dip containing Lacticin 3147 reduced counts of S. aureus (80\%), Streptococcus dysgalactiae (97\%), and Streptococcus uberis (90\%), which are major mastitis-causing pathogens. Other bacteriocins exhibiting antimicrobial activity against $S$. aureus and Streptococcus agalactiae are nisin U, kenyacin 404, morricin 269, uberolysin, bacteriocin ST91KM, kurstacin 287, Pep5, entomocin, epidermin, epilancin K7, epicidin 280, and aureocins A70, A53, and 215FN (Ahmad et al., 2017). Another nisin-based formulation named Preva ${ }^{\circledR}$ containing $25 \mu \mathrm{g} / \mathrm{mL}$ of active pharmaceutical ingredient was released to the veterinary market in the US, and it is prescribed for topical use on dogs, cats, and horses with dermatological problems associated with bacterial infections (Field et al., 2015).

- Plants. The substances produced by plants that exhibit antimicrobial activity belong to different chemical compound classes, e.g., flavonoids, alcohols, aldehydes, esters, ketones, acids, and aromatic compounds (González-Mas et al., 2019). In general, essential oils are a mixture of volatile chemical compounds belonging to different chemical groups, with usually one main component exhibiting antimicrobial properties alone (Gucwa et al., 2018) or in synergistic interaction with other compounds (Sagdic et al., 2013; Singh and Sharma, 2015). Many interesting examples of essential oils exhibiting antibacterial and antifungal properties do exist, with geranium, cinnamon, and thyme essential oils being the most extensively studied. The essential oil from thyme, extracted from Thymus vulgaris, is abundant in thymol and carvacrol and exhibits high activity against fungi, such as Candida albicans, Candida tropicalis, and also Fusarium spp. and Aspergillus spp. Ge- 
ranium essential oils (extracted from Pelargonium graveolens), rich in geraniol (an acyclic monoterpenoid), exhibit high activity against pathogenic fungi, such as C. albicans, Candida glabrata, and C. tropicalis. Different types of cinnamon essential oil, rich in cinnamaldehyde, have also been known to be active against fungi, such as C. albicans, Candida parapsilopsis, Candida riferii, C. tropicalis, and C. glabrata (D'Agostino et al., 2019). Lemon oil is also known for its antifungal properties (Szweda et al., 2015). Essential oils are also very well-known for their activity against bacterial pathogens, such as $P$. aeruginosa, E. coli, S. aureus (even MRSA), Staphylococcus epidermidis (Szweda et al., 2018), K. pneumoniae, and M. tuberculosis. A comprehensive review on this topic has been already presented (Raut and Karuppayil, 2014). In the human diet, parts of many plants may act in several ways. Many spices that improve the taste of food also contain microbiologically active compounds, e.g., black pepper - four antioxidant and 14 bactericide compounds; garlic - nine antioxidant, five antiviral, and 13 bactericide compounds; oregano - 14 antioxidant, 11 antiviral, and 19 bactericide compounds; while rosemary - 12 antioxidant, 10 antiviral, and 19 bactericide compounds. Some plants are also used in farm animals as growth and health promoters due to their flavor- or appetite-enhancing properties or due to their immunostimulatory, antiviral, or antibacterial effects. In addition to their antimicrobial properties, plant derivatives stimulate the immune system: Acemannan from Aloe vera acts as immunostimulators (Djeraba and Quere, 2000), while Aloe secundiflora increases the antibody titer and IL-6 concentration (Waihenya et al., 2002) in broiler chickens. Moreover, an extract of cinnamon, oregano, and thyme causes a reduction in fecal coliforms with no immunostimulatory effect (Namkung et al., 2004), while $\beta$-glucan increases lymphocyte proliferation in pigs (Mao et al., 2005).

- Animals. Cationic antimicrobial compounds, e.g., histatin, defensin, cathelicidins, trombocidin, and ranalexin, are positively charged compounds with antimicrobial activity produced by different kinds of animals, from bacteria to vertebrates. They naturally protect the organism from infections. In review articles, the sites of expression and modes of action of defensins and cathelicidins were described and the potential use of antimicrobial peptides (AMPs) against pathogens was stressed (Clark et al., 1994; De Smet and Contreras, 2005; Bagnicka et al., 2010; Kościuczuk et al., 2012; Jarczak et al., 2013). Since the beginning of the 21st century, many clinical trials have been conducted with the hope of using AMPs in medicine. Some AMPs, such as polymyxin and gramicidin, have been in use for many years (https://patents.google.com/patent/US2822314A/en). As summarized by de Breij et al. (2018), 16 synthetic AMPs are in preclinical or in different stages of clinical studies. In almost all of the studies, the peptides showed strong killing potency against $S$. aureus and $P$. aeruginosa. Unfortunately, their activity strongly depended on saline concentration, such that the activity was reduced based on the physiological concentration of the sodium phosphate buffer. SAAP-148 (derived from the human analog of cathelicidin LL-37), iseganan (or IB-367 - a synthetic analog of protegrin-1 isolated from porcine neutrophils), KABT-AMP (a synthetic 22-amino acid helical cationic peptide rich in lysine), and pexiganan (or MSI- 
78 - a synthetic analog of magainin found in frog skin [Xenopus laevis]) showed the highest efficiency against both studied bacteria. However, use of the synthetic AMP iseganan in preventing ventilator-associated pneumonia failed in Phase III of a clinical trial (ClinicalTrials.gov Identifier: NCT00118781; https://clinicaltrials. gov/ct2/show/results/NCT00118781). Other synthetic AMPs in preclinical studies were hepcidin-25, HP135, plectasin, POL7001, POL 7080, S-Thanatin, and DKP 060 (Andrès, 2012; de Breij et al., 2018; Naafs, 2018). Omiganan was in Phase III of a clinical trial (ClinicalTrials.gov Identifier: NCT00231153; https://clinicaltrials.gov/ct2/show/NCT00231153) to develop a topical gel for preventing fungal and mold infections, especially catheter-associated infections (Fritsche et al., 2008 a, b). Moreover, the activity of omiganan (Omiganan [CLS001] Topical Gel) against moderate to severe inflammatory acne vulgaris was tested (ClinicalTrials.gov; Identifier: NCT02571998; https://clinicaltrials.gov/ct2/show/NCT02571998). However, as stressed by Mahlapuu et al. (2016) and Naafs (2018), its clinical use was found to be unsatisfactory. The disinterest of large pharmaceutical companies in drugs derived from AMPs may be due to the high costs of their production (e.g., proteolysis during production). The hope is that small biopharma companies will pursue these drugs instead. However, the safety and toxicity of their oral administration are still unknown, and there are many concerns about their introduction in clinical use (though the nephrotoxicity and neurotoxicity of polymyxins administered intravenously is already known). Moreover, because they are peptides, their administration is difficult - proteolytic degradation and poor penetration of mucosa cause low oral bioavailability - and they are also very sensitive to environmental conditions. They are rapidly removed from circulation due to hepatic and renal clearance, as well as degradation by proteolytic enzymes in blood plasma. Therefore, they are mainly used in skin, wound, ear, and eye infections or for chronic leg ulcers (topical applications).

- Animal products.

- Honey. It is widely recognized that honey has a comprehensive and nutritional effect on humans, with the most famous being New Zealand's manuka honey, which shows non-peroxide antibacterial activity (Weston, 2000). One of its most important characteristics is its ability to strengthen the immune system (Kuś et al., 2016; Pajor et al., 2018). Honey has antibacterial properties due to the presence of thermostable antibiotic substances (Godlewska and Świsłocka, 2015). Alcohol honey solutions (e.g., methanol and ethanol) show a wide spectrum of antibacterial activity against aerobic, anaerobic, Gram-positive (e.g., S. aureus, Bacillus subtilis, Bacillus cereus, E. faecalis, and Micrococcus luteus), and Gram-negative (e.g., E. coli, P. aeruginosa, and Salmonella typhi) bacteria. This effect may be bactericidal or bacteriostatic, depending on the concentration used, and is conditioned by flavonoids, benzoic acid, and cinnamic acid (Khan et al., 2018). The medical type of honey used in the studies of Blair et al. (2009) was characterized by antimicrobial activity even against resistant bacterial strains.

- Propolis, which consists of different chemical substances (phenolic acids and esters, flavonoids, terpenes, amino acids, caffeic acid phenyl esters, aromatic aldehydes, alcohols, fatty acids, and steroids), is a resinous solid collected by bees 
from buds, exudates, and other parts of plants mixed with bee saliva, enzymes, and beeswax used in nature to protect the beehive (Fangio et al., 2019). Despite the differences in composition, which depend on geographical region, the plants visited by bees, climate, and season, all propolis extracts exhibit similar antibacterial, antifungal, antiviral, or anti-inflammatory properties. In terms of antibacterial activity, the most important factors are its flavonoids and phenolic compound content. The variety of antibacterial compounds combined may act on the bacterial cell in different ways (e.g., by disrupting membrane potential or decreasing bacterial mobility), thus there is only a slight chance for propolis to induce resistance. Many studies on propolis's antibacterial properties have been conducted, revealing its vast potential, against even multidrug-resistant bacteria. In general, these studies have presented propolis's higher activity against Grampositive bacteria (e.g., S. aureus, Listeria monocytogenes, E. faecalis, Streptococcus mutans, M. tuberculosis and Bacillus spp.) compared to Gram-negative bacteria (e.g., K. pneumoniae, E. coli, P. aeruginosa, Aeromonas spp., and Salmonella spp.) (Nam et al., 2015; Oliveira et al., 2017; Przybyłek and Karpiński, 2019). Different practical applications of propolis have been analyzed, e.g., different types of propolis may be active also on clinical isolates of staphylococci (including MRSA), while others may prevent and/or eradicate staphylococcal biofilm formation. Other types of propolis may interact with commonly used antibiotics, such as amikacin, kanamycin, or tetracycline (Grecka et al., 2019).

The chemical modification and reuse of already known antibiotics is other alternative approach to overcoming drug resistance. For example, oritavancin, a vancomycin derivative, is active against vancomycin-resistant Gram-positive bacteria (Moellering, 2011). Combined therapies - meaning, the use of different adjuvants to achieve a therapeutic goal - are another alternative. Combined therapies include the use of more than one antibiotic, the use of an antibiotic along with a synergistic non-antibiotic, or the use of substances that inhibit the resistance gene. Augmenting a treatment can be very beneficial because it increases the possibility of using existing and previously approved antibiotics. Combined therapies include: 1) inhibitors of drug resistance mechanisms - $\beta$-lactam antibiotics administered with $\beta$-lactamase inhibitors (e.g., commonly used amoxicillin with clavulanic acid); 2) a set of inhibitors of the efflux pump responsible for removing an antibiotic from the cell; 3 ) phage therapies combined with antibiotics (e.g., cephalosporin has been shown to increase cell lysis caused by phages); and 4) bacteriocins combined with antibiotics (e.g., the synergy between the polymyxin group of antibiotics and bacteriocins to fight Gramnegative pathogens) (Allen et al., 2014).

Nanoscale materials such as copper, zinc, magnesium, silver, or gold nanoparticles may also be useful as an alternative agent against bacterial infections. The particular mechanisms of nanoparticle action depend on their type, shape, and size. Copper and silver nanomaterials have a broad spectrum of activity on Gram-positive and Gram-negative bacteria, fungi, viruses, and protozoa. They are used for many healthcare and hygiene care purposes. The possibility of using these nanoparticles in the fight against multidrug-resistant bacterial strains seems extremely interesting (Ibrahim et al., 2012). Products containing nanosilver are ef- 
fective against a vast number of microorganisms, including pathogenic bacteria like $S$. aureus, $P$. aeruginosa, and $S$. pyogenes, as well as fungi like C. albicans, Phoma glomerata, and Trichoderma spp. (Wolny-Koładka et al., 2018). Lopez-Carrizales et al. (2018) noticed the antibacterial effect of silver nanoparticles on Enterobacteriaceae, especially E. coli, in urinary tract infections. They found that these infections could be treated with silver nanoparticles even when multidrug-resistant microorganisms were present. However, some other authors found silver nanoparticles to have toxic effects on cells, thus more research is essential to eliminate side effects (Braydich-Stolle et al., 2005). Yoon et al. (2007) demonstrated that the antimicrobial action of copper nanoparticles was better than that of silver ones. Gold nanoparticles may also be used as a potential antibacterial factor, but their central role is to help to deliver the drug (e.g., antibiotics) directly to bacterial cells or to facilitate the photodynamic destruction of bacteria. It has been shown that nanogold conjugates with vancomycin are approximately 50 times more active against E. faecalis and Enterococcus faecium. Gold nanoparticles also enhance the absorption of light during photodynamic therapy - their conjugates with dye are more active than dye alone (Kurek et al., 2011). Despite the high antimicrobial activity of nanometals explained in vivo studies, nanomaterials are not being used in agriculture for bactericidal or bacteriostatic tasks. The potential advantages of their use are still marginal, and they have not been commercialized to a significant extent, compared to other industrial sectors (Dwivedi et al., 2016).

Bacteriophage therapy may be another potential strategy to overcome bacterial resistance to classical antibiotics. The use of bacteriophages may have several advantages: 1) bacteriophages act selectively only on targeted bacteria, leaving the host cells and beneficial gut microbiota untouched (i.e., low toxicity and low probability of side effects); 2) bacteriophages can increase their number directly at the site of infections in time; 3 ) bacteriophages may be used as treatment agents for antibioticresistant and antibiotic-sensitive bacteria; 4) there is a lack of cross-resistance with antibiotics; 5) new bacteriophages with novel antimicrobial properties are still being discovered, in contrast to new antibiotics; and 6) bacteriophages can be administered via animal husbandry to only a few animals, and because they can move between animals, they decrease the necessary therapeutic dose for the flock and also create resistance to a particular infection across the flock (Loc-Carrillo and Abedon, 2011; Pirisi, 2000). Some of these advantages are also creating problems with finding appropriate therapeutic strategies - the high specificity of bacteriophages requires searching for a particular phage or even a cocktail of phages (several phages mixed to broaden the range of activity) for a specific pathogen. It is also essential to make sure that phages selected for study/therapy are pure enough, e.g., that endotoxins are removed from the mixture or that they are not coding any bacterial virulence factors. Moreover, for phage therapy, the host's bactericidal range is more important than its reproductive range; however, it should be noted that bacteriophages are designed for in situ phage virion production - they increase their number depending on place. It has also been noted that bacteria can act against phages via different mechanisms, such as adsorption resistance, restriction-modification systems, or phage growth limitation systems (Nobrega et al., 2015). Bacteriophages may be administered orally, injected, or ap- 
plied directly (locally). The success of therapy depends on the sufficient quantity of antimicrobial agents able to reach infected cells, which is relatively easy for bloodstream, blood tissue, or local soft tissue infections, but may be problematic in the case of nonblood tissue (Dąbrowska and Abedon, 2019). Phages applied solely or as a cocktail may effectively control necrotic enteritis in chicken broilers and improve feed conversion and weight gain (Miller et al., 2010), which may also improve the growth performance in pigs (Kim et al., 2014). Moreover, it has been proven that a cocktail of phages targeting pathogens, including Salmonella spp., E. coli, S. aureus, and Clostridium perfringens, could improve average daily feed intake of grower pigs (Kim et al., 2014). Bacteriophages have also been successfully tested as a treatment option for zoonotic diseases caused by pathogens such as Salmonella enteritidis in laying hens (80\% reduction of bacteria prevalence) (Borie et al., 2009), or E. coli O157: H7 in sheep (bacterial population was reduced in the cecum and colon, while rumen microbiota remains unchanged) (Callaway et al., 2008). In predatory bacteria treatment, bacterial species that feed on other bacterial species, e.g., motile Bdellovibrio and bdellovibrio-like bacteria, are used. Predatory bacteria prey on Gram-negative bacteria for energy and nutrients. At first, these bacterial species were investigated as a means of protecting catheters from biofilm-forming microorganisms. Now, they are being investigated for clinical use to fight drug-resistant bacterial species, such as A. baumannii, E. coli, K. pneumoniae, P. aeruginosa, and Pseudomonas putida. However, they can also affect commensal microbiota. Moreover, the bacteria from the Bdellovidio genus can colonize the mammalian intestinal tract. Predatory bacteria are far from being used therapeutically, but they seem to be a promising alternative to conventional antibiotics (Allen et al., 2014).

However, disease prevention is the best solution. Modulating the gut microbiota or immunization are two prophylactic strategies. Gut microbiota coexist with the organism, modulating the immune system, improving nutrient utilization, eliminating pathogens, and preventing pathogen colonization (e.g., Clostridium difficile infections after severe antibiotic therapy). Probiotics and prebiotics can be used to modulate gut microbiota. A normal diet can be supplemented by cultures of beneficial microorganisms (probiotics) or by foods containing substances promoting gut microbiota growth (prebiotics) (Allen et al., 2014). Immunization of the organism to promote host resistance is also very important. Vaccines in earlier times were prepared with attenuated whole cells; now, they are being replaced by vaccines prepared with the use of genetic engineering tools. Vaccines are prepared from safer products and are made with polysaccharide cell capsules, including proteins, toxoids, and protein carriers. Moreover, immunizations with polyclonal or monoclonal antibodies are also being developed, which can be used not only for immunization but also for treatment in combination with drugs (Lloyd, 2012).

Summing up, nowadays, human healthcare and agricultural facilities are facing the life-threatening problem of antibiotic resistance among pathogens. Commonly used antibiotics have become ineffective against typical infections. Moreover, the pace of identifying new, potentially useful antimicrobials is much slower than during the 'golden era' of antibiotics. Microorganisms develop and evolve resistance mechanisms much faster than new tools to fight them are introduced into clinical 
application. The threat of a 'superbug' outbreak remains. Bacterial antibiotic resistance has become a serious, worldwide health problem. It results in longer hospital stays and higher healthcare costs, and as it spreads, morbidity and mortality rates increase. The place we live in also plays a role in resistance. According to research in the Netherlands published in 2014, antibiotics are less effective for patients in rural areas than for patients in big cities. Though further research on this topic must be conducted, we can speculate that this difference in efficacy is somehow related to the mass use of antibiotics on farms (both in animals and plants). Very strict rules regarding antibiotic use by farmers should be established and enforced, since their farms produce food (de Jong et al., 2014).

Moreover, we are now experiencing the effects of climate change and global warming, and the influence of global warming on increased antibiotic resistance in pathogenic bacteria has been reported. MacFadden et al. (2018) found differences in the prevalence of antibiotic resistance genes with regard to latitude, which is directly connected with temperature and humidity: they found a higher prevalence of these genes in southern than in northern parts of the United States. Moreover, among European countries, the highest percentages of resistant strains of $S$. aureus are in Italy and France (Stefani and Varaldo, 2003). These findings also confirm those of a conference report made by a German-Dutch team, which stressed that antibiotic resistance is a threat to Europe, with countries of the Mediterranean Basin being in the greatest danger. They conducted their study in 30 countries across Europe, taking into consideration socioeconomic factors and healthcare systems. The reason for this geographic disparity regarding increased resistance could be the higher warm-season temperature, which may help in the horizontal transfer of antibiotic resistance genes (The European Union Summary Report on antimicrobial resistance in zoonotic and indicator bacteria from humans, animals and food in 2017 (2019)). As MacFadden et al. (2018) noted, temperature is also one of the strongest modifiers of the bacterial growth rate and could also be increasing the rate of transfer of resistant bacteria between animals and humans. Although the overuse of antibiotics both in agriculture and in human treatment influences the spread of antibiotic resistance genes, it seems that global warming may also influence the increasing resistance of bacteria to known antibiotics.

\section{Conclusions}

Many studies are being conducted to search for new antibiotics, and clinical trials are underway to test them. A variety of strategies to fight microbes exist, but we are a long way from approving them as therapies. Furthermore, besides developing new strategies to fight pathogenic bacteria, multidrug-resistant pathogens have to be tracked and isolated to prevent the uncontrolled spreading of resistant genes. The antimicrobial activity of some substances contained in plant and animal products have been known since ancient times. At the beginning of this century, some of these, such as antimicrobial peptides, were considered very promising candidates for becoming new antibiotics. However, many preclinical and clinical trials ended without positive results. Unfortunately, there is still a long way to go, but we have many new approaches and tools to fight resistant pathogens. 


\section{References}

A study to evaluate the safety and efficacy of Omiganan (CLS001) topical gel versus vehicle in female subjects with moderate to severe acne vulgaris. ClinicalTrials.gov.

A d e g o k e A.A., F a l e y e A.C., S ing h G., S ten s tröm T.A. (2017). Antibiotic resistant superbugs: assessment of the interrelationship of occurrence in clinical settings and environmental niches. Mol. Basel Switz., 22: 29.

A h m a d V.,Kh a n M.S.,J a m a l Q.M.S.,A 1 z o h a i r y M.A.,A $1 \mathrm{~K}$ a r a a w i M.A.,S i d d i qu i M.U. (2017). Antimicrobial potential of bacteriocins: in therapy, agriculture and food preservation. Int. J. Antimicrob. Agents, 49: 1-11.

A l c o c k B.P., R a phen y a A.R., L a u T.T.Y., Ts ang K.K., B o u c hard M., E d a l a t m a nd A., Huynh W., Nguyen A.-L.V., Cheng A.A., Li u S., et al. (2019). CARD 2020: antibiotic resistome surveillance with the comprehensive antibiotic resistance database. Nucleic Acids Res., gkz935.

A 11 e n H.K., Tr a c h s e 1 J., L o o ft T., C a s e y T.A. (2014). Finding alternatives to antibiotics. Ann. N. Y. Acad. Sci., 1323: 91-100.

A m in ov R.I. (2010). A brief history of the antibiotic era: lessons learned and challenges for the future. Front. Microbiol., 1: 134.

A n d a m C.P., F o u rn i e r G.P., G o g a r t e n J.P. (2011). Multilevel populations and the evolution of antibiotic resistance through horizontal gene transfer. FEMS Microbiol. Rev., 35: 756-767.

Andrès E. (2012). Cationic antimicrobial peptides in clinical development, with special focus on thanatin and heliomicin. Eur. J. Clin. Microbiol. Infect. Dis. Off. Publ. Eur. Soc. Clin. Microbiol., 31: $881-888$.

Arseculeratne S.N., Arseculeratne G. (2017). A re-appraisal of the conventional history of antibiosis and Penicillin. Mycoses, 60: 343-347.

B a gni cka E., S trzałkows ka N., Jóźwik A., Krzyżewski J., Horbańczuk J., Zwie rzchowski L. (2010). Expression and polymorphism of defensins in farm animals. Acta Biochim. Pol., 57: 487-497.

B a 11 A.P., Gra y J.A., M u r d o c h J.M. (1978). The natural penicillins - Benzylpenicillin (Penicillin G) and Phenoxymethylpenicillin (Penicillin V). In: Antibacterial drugs today. Ed. Springer, Dordrecht, pp. 6-18.

B a r n a J.C.J., W i 11 i a m s D.H. (1984). The structure and mode of action of glycopeptide antibiotics of the vancomycin group. Ann. Rev. Microbiol., 38: 339-357.

B e nne t t J.W., Chung K.T. (2001). Alexander Fleming and the discovery of penicillin. Adv. Appl. Microbiol., 49: 163-184.

B e n t l e y R. (1997). Microbial secondary metabolites play important roles in medicine; prospects for discovery of new drugs. Perspect. Biol. Med., 40: 364-394.

B l a ir S.E., C o k c e t in N.N., H a r ry E.J., C a r t e r D.A. (2009). The unusual antibacterial activity of medical-grade Leptospermum honey: antibacterial spectrum, resistance and transcriptome analysis. Eur. J. Clin. Microbiol. Infect. Dis. Off. Publ. Eur. Soc. Clin. Microbiol., 28: 1199-1208.

Borie C., Sánchez M.L., Navarro C., Ramírez S., Morales M.A., Retamales J., R o b e s o n J. (2009). Aerosol spray treatment with bacteriophages and competitive exclusion reduces Salmonella Enteritidis infection in chickens. Avian Dis., 53: 250-254.

Braydich-S tolle L., Hus s a in S., S chlager J.J., Ho fman n M.-C. (2005). In vitro cytotoxicity of nanoparticles in mammalian germline stem cells. Toxicol. Sci. Off. J. Soc. Toxicol., 88: 412-419.

Bruin J., A ar M. van der, Overdevest I., K luytmans J., Diederen B. (2010). P24.06 Prevalence of highly resistant Enterobacteriaceae including ESBLs in retail meat. J. Hosp. Infect., 76: S69.

C all aw a y T.R., Edrington T.S., B rabban A.D., Anders on R.C., R os s man M.L., Eng l e r M.J., Carr M.A., Genoves e K.J., Ke en J.E., L o o per M.L., K ut ter E.M., N is b e t D.J. (2008). Bacteriophage isolated from feedlot cattle can reduce Escherichia coli O157: H7 populations in ruminant gastrointestinal tracts. Foodborne Pathog. Dis., 5: 183-191.

C a r s O., He din A., He d d in i A. (2011). The global need for effective antibiotics-moving towards concerted action. Drug Resist. Updat., 14: 68-69. 
CDC - Centers for Disease Control and Prevention (2019). The biggest antibiotic-resistant threats in the U.S. http://dx.doi.org/10.15620/cdc:82532

Chen C., Guron G.K., Pruden A., P onder M., Du P., Xi a K. (2018). Antibiotics and antibiotic resistance genes in bulk and rhizosphere soils subject to manure amendment and vegetable cultivation. J. Environ. Qual., 47: 1318-1326.

Chopra I., R oberts M. (2001). Tetracycline antibiotics: mode of action, applications, molecular biology, epidemiology of bacterial resistance. Microbiol. Mol. Biol. Rev., 65: 232-260.

Cirz R.T., Ch in J.K., A ndes D.R., d e Cré cy - L a gard V., Cra ig W.A., R o m e s berg F.E. (2005). Inhibition of mutation and combating the evolution of antibiotic resistance. PLoS Biol., 3 : e176.

C 1 a r k D.P., D u re 11 S., M a 1 o y W.L., Z a s 1 o ff M. (1994). Ranalexin. A novel antimicrobial peptide from bullfrog (Rana catesbeiana) skin, structurally related to the bacterial antibiotic, polymyxin. J. Biol. Chem., 269: 10849-10855.

C o o k K.L., N e t th i s ing he A.M.P., Gilfille n R.A. (2014). Detection of pathogens, indicators, antibiotic resistance genes after land application of poultry litter. J. Environ. Qual., 43: 1546.

Coppo E., Del Bono V., Ventura F., Camera M., Orengo G., Viscoli C., Marches e A. (2014). Identification of a New Delhi metallo- $\beta$-lactamase-4 (NDM-4)-producing Escherichia coli in Italy. BMC Microbiol., 14: 148.

Cost e rton J.W., Cheng K.J., G e e s e y G.G., L a d d T.I., N i c kel J.C., D a s g u p ta M., M a r r i e T.J. (1987). Bacterial biofilms in nature and disease. Annu. Rev. Microbiol., 41: 435-464.

Cotte r P.D., Hill C., R os s R.P. (2005). Bacteriocins: developing innate immunity for food. Nat. Rev. Microbiol., 3: 777-788.

Crispie F., Flynn J., R os s R.P., Hill C., Me a ney W. (2004). Update on the development of a novel dry cow therapy using a bismuth-based intramammary teat seal in combination with the bacteriocin lacticin 3147. Ir. Vet. J., 57: 652-656.

Crispie F., Twomey D., Flynn J., Hill C., Ross P., Meaney W. (2005). The lantibiotic lacticin 3147 produced in a milk-based medium improves the efficacy of a bismuth-based teat seal in cattle deliberately infected with Staphylococcus aureus. J. Dairy. Res., 72: 159-167.

Cully M. (2014). Public health: The politics of antibiotics. Nature, 509: S16-S17.

D'Agostino M., Tesse N., Frippiat J.P., Machouart M., Debourgogne A. (2019). Essential oils and their natural active compounds presenting antifungal properties. Molecules, 24: 3713 .

D ' Cos t a V.M., K ing C.E., K a la n L., Morar M., S ung W.W.L., S c hw ar z C., Froes e D., $\mathrm{Zazu}$ a G., Ca $1 \mathrm{mels}$ F., D e b ru yne R., et al. (2011). Antibiotic resistance is ancient. Nature, 477: $457-461$.

D ą b r o w s k a K., A b e d o n S.T. (2019). Pharmacologically aware phage therapy: pharmacodynamic and pharmacokinetic obstacles to phage antibacterial action in animal and human bodies. Microbiol. Mol. Biol. Rev., 83.

Davi es J., D a vi es D. (2010). Origins and evolution of antibiotic resistance. Microbiol. Mol. Biol. Rev., 74: 417-433.

de Breij A., Riool M., Cordfunke R.A., Malanovic N., de Boer L., Koning R.I., Ravensbergen E., Franken M., van der Heijde T., Boekema B.K., et al. (2018). The antimicrobial peptide SAAP-148 combats drug-resistant bacteria and biofilms. Sci. Transl. Med., 10.

de Jong J., Bos J.H.J., de Vries T.W., de Jong-van den Berg L.T.W. (2014). Use of antibiotics in rural and urban regions in The Netherlands: an observational drug utilization study. BMC Public Health, 14: 677.

De S met K., Contreras R. (2005). Human antimicrobial peptides: defensins, cathelicidins and histatins. Biotechnol. Lett., 27: 1337-1347.

D e s a i J.V., M i t c he 11 A.P., A n d e s D.R. (2014). Fungal biofilms, drug resistance, recurrent infection. Cold Spring Harb. Perspect. Med., 4: a019729.

D ibner J.J., R i c hards J.D. (2005). Antibiotic growth promoters in agriculture: history and mode of action. Poultry Sci., 84: 634-643.

D j e r a b a A., Qu ere P. (2000). In vivo macrophage activation in chickens with Acemannan, a complex carbohydrate extracted from Aloe vera. Int. J. Immunopharmacol., 22: 365-372. 
D ow 1 ing P.M. (2013 a). Peptide Antibiotics. In: Antimicrobial Therapy in Veterinary Medicine. John Wiley \& Sons, Ltd, pp. 189-198.

D o w 1 in g P.M. (2013 b). Miscellaneous Antimicrobials. In: Antimicrobial Therapy in Veterinary Medicine. John Wiley \& Sons, Ltd, pp. 315-332.

D u c k e t t S. (1999). Ernest Duchesne and the concept of fungal antibiotic therapy. Lancet Lond. Engl., 354: 2068-2071.

D u ew el he n ke N., Krut O., E y s el P. (2007). Influence on mitochondria and cytotoxicity of different antibiotics administered in high concentrations on primary human osteoblasts and cell lines. Antimicrob. Agents Chemother., 51: 54-63.

D u four D., L e ung V., Lé ve s qu e C.M. (2010). Bacterial biofilm: structure, function, antimicrobial resistance. Endod. Top., 22: 2-16.

Dw i vedi S., S a qu ib Q., A l - K h e d h a iry A.A., M u s a r r a t J. (2016). Understanding the role of nanomaterials in agriculture. In Microbial inoculants in sustainable agricultural productivity. Springer, New Delhi, pp. 271-288.

F ang i o M.F., Orallo D.E., Gende L.B., Churio M.S. (2019). Chemical characterization and antimicrobial activity against Paenibacillus larvae of propolis from Buenos Aires province, Argentina. J. Aplic. Res., 58: 626-638.

F i eld D., G a u d in N., Ly on s F., O ' C o n n or P.M., C ot te r P.D., Hi 11 C., R o s s R.P. (2015). A bioengineered Nisin derivative to control biofilms of Staphylococcus pseudintermedius. PLoS One, 10: e0119684.

F le m in $g$ A. (1929). On the antibacterial action of cultures of a penicillium, with special reference to their use in the isolation of B. influenzce. Br. J. Exp. Pathol., 10: 226-236.

Frieri M., Kumar K., B outin A. (2017). Antibiotic resistance. J. Infect. Public Health, 10: 369-378.

Frits che T.R., Rhomberg P.R., S a der H.S., Jones R.N. (2008 a) Antimicrobial activity of omiganan pentahydrochloride against contemporary fungal pathogens responsible for catheter-associated infections. Antimicrob. Agents Chemother., 52: 1187-1189.

Frits che T.R., Rhomberg P.R., S a d e r H.S., J on es R.N. (2008 b). Antimicrobial activity of omiganan pentahydrochloride tested against contemporary bacterial pathogens commonly responsible for catheter-associated infections. J. Antimicrob. Chemother., 61: 1092-1098.

Giguèr e S., D ow 1 ing P.M. (2013). Fluoroquinolones. In: Antimicrobial Therapy in Veterinary Medicine. John Wiley \& Sons, Ltd, pp. 295-314.

Godlewska M., Św isłocka R. (2015). The physicochemical and antimicrobial properties of honey from the region of Podlasie (in Polish). Kosmos, 64: 347-352.

González-M a s M.C., R a mbla J.L., Lóp ez-Gresa M.P., B lázque z M.A., Grane 11 A. (2019). Volatile compounds in citrus essential oils: a comprehensive review. Front. Plant Sci., 10.

Grecka K., Kuś P.M., Okińczy c P., Worobo R.W., Walkusz J., S zwe da P. (2019). The anti-staphylococcal potential of ethanolic Polish propolis extracts. Molecules, 24: 1732.

Gucwa K., Milewski S., Dymerski T., Szweda P. (2018). Investigation of the antifungal activity and mode of action of Thymus vulgaris, Citrus limonum, Pelargonium graveolens, Cinnamomum cassia, Ocimum basilicum, and Eugenia caryophyllus essential oils. Molecules, 23: 1116.

H a n o c k R.E. (1997). Peptide antibiotics. Lancet Lond. Engl., 349: 418-422.

H e u e r H., S chmitt H., S m a lla K. (2011). Antibiotic resistance gene spread due to manure application on agricultural fields. Curr. Opin. Microbiol., 14: 236-243.

Hoffman S.J., Outterson K., Røttingen J.-A., Cars O., Clift C., Rizvi Z., Rotberg F., Tom s on G., Z orzet A. (2015). An international legal framework to address antimicrobial resistance. Bull. World Health Organ., 93: 66.

Holmes A.H., Moore L.S.P., Sundsfjord A., Steinbakk M., Regmi S., Karkey A., Gu e r i n P.J., P i d d o c k L.J.V. (2016). Understanding the mechanisms and drivers of antimicrobial resistance. Lancet, 387: 176-187.

I b r a h i m M.E., B i 1 a 1 N.E., H a m i d M.E. (2012). Increased multi-drug resistant Escherichia coli from hospitals in Khartoum state, Sudan. Afr. Health Sci., 12: 368-375.

Jamal M., Ahmad W., Andleeb S., Jalil F., Imran M., Nawaz M.A., Hus sain T., Ali M., R a fi q M., Ka mil M.A. (2018). Bacterial biofilm and associated infections. J. Chin. Med. Assoc., 81: 7-11. 
Jarczak J., Kościuczuk E.M., Li sowski P., Strzałkow ska N., Jóźwik A., Horbań c zuk J., Krzyżew s ki J., Z wi erzchowski L., B a g n i cka E. (2013). Defensins: natural component of human innate immunity. Hum. Immunol., 74: 1069-1079.

J o nes O.A., L e s t e r J.N., Voulvoul is N. (2005). Pharmaceuticals: a threat to drinking water? Trends Biotechnol., 23: 163-167.

J o u a n n a J. (2012). Greek medicine from Hippocrates to Galen: Selected papers. Brill.

K a p o or G., S a ig a l S., E 1 on g a va n A. (2017). Action and resistance mechanisms of antibiotics: A guide for clinicians. J. Anaesthesiol. Clin. Pharmacol., 33: 300-305.

Khan S.U., Anjum S.I., Rahman K., Ans ari M.J., Khan W.U., Ka mal S., Khattak B., Muham mad A., Khan H.U. (2018). Honey: Single food stuff comprises many drugs. Saudi J. Biol. Sci., 25: 320-325.

K i m K.H., In g a le S.L., K i m J.S., L e e S.H., L e e J.H., K w o n I.K., C h a e B.J. (2014). Bacteriophage and probiotics both enhance the performance of growing pigs but bacteriophage are more effective. Anim. Feed. Sci. Tech., 196: 88-95.

Klostermann K., Crispie F., Flynn J., Me an ey W.J., P a u 1 R.R., Hill C. (2010). Efficacy of a teat dip containing the bacteriocin lacticin 3147 to eliminate Gram-positive pathogens associated with bovine mastitis. J. Dairy. Res., 77: 231-238.

K o n K., R a i M. (2016). Antibiotic resistance: mechanisms and new antimicrobial approaches. Academic Press.

Kośc i u c zuk E.M., Li s ow sk i P., Jarczak J., Strzałkowska N., Jóźwi k A., Horbańczuk J., Krzyżewski J., Zwierzchowski L., Bagnicka, E. (2012). Cathelicidins: family of antimicrobial peptides. A review. Mol. Biol. Rep., 39: 10957-10970.

Kou idhi B., A l Qu ras hi Y.M.A., C h a i e b K. (2015). Drug resistance of bacterial dental biofilm and the potential use of natural compounds as alternative for prevention and treatment. Microb. Pathog., 80: 39-49.

K u bi ck i J. (2013). History of the syphilis (in Polish). Puls Uczel., 3: 37-39.

Kurek A., Grudniak A.M., Kraczkiewicz-Dowjat A., Wolska K.I. (2011). New antibacterial therapeutics and strategies. Pol. J. Microbiol., 60: 3-12.

K u ś P.M., S zw e da P., J e rk ovi ć I., T u ber o s o C.I.G. (2016). Activity of Polish unifloral honeys against pathogenic bacteria and its correlation with colour, phenolic content, antioxidant capacity and other parameters. Lett. Appl. Microbiol., 62: 269-276.

L a n d e c k e r H. (2016). Antibiotic resistance and the biology of history. Body Soc., 22: 19-52.

Levy S.B., Marshall B. (2004). Antibacterial resistance worldwide: causes, challenges and responses. Nat. Med., 10: 122-129.

L e w is K. (2001). Riddle of biofilm resistance. Antimicrob. Agents Chemother., 45: 999-1007.

L i u B., P op M. (2009). ARDB - Antibiotic Resistance Genes Database. Nucleic Acids Res., 37 : D443-D447.

L 1 o y d D.H. (2012). Alternatives to conventional antimicrobial drugs: a review of future prospects. Vet. Dermatol., 23: 299-304, e59-60.

Loc-Carrillo C., Abedon S.T. (2011). Pros and cons of phage therapy. Bacteriophage, 1: 111-114.

Lopez-C arrizale s M., Vela s co K.I., C a stillo C., F lores A., M a gaña M., M a rtin ez - Cast a non G.A., Martinez-Guti errez F. (2018). In vitro synergism of silver nanoparticles with antibiotics as an alternative treatment in multiresistant uropathogens. Antibiot. Basel Switz., 7: 50 .

MacFadden D.R., McGough S.F., Fisman D., Santillana M., Brownstein J.S. (2018). Antibiotic resistance increases with local temperature. Nat. Clim. Change, 8: 510-514.

Mahlapuu M., Håkans s on J., Ringstad L., Björn C. (2016). Antimicrobial peptides: an emerging category of therapeutic agents. Front. Cell. Infect. Microbiol., 6: 194.

M a o X.F., P i a o X.S., L a i C.H., L i D.F., X in g J.J., S h i B.L. (2005). Effects of $\beta$-glucan obtained from the Chinese herb Astragalus membranaceus and lipopolysaccharide challenge on performance, immunological, adrenal, somatotropic responses of weanling pigs. J. Anim. Sci., 83: 2775-2782.

Martíne z J.L., B a que ro F., A nder s s o n D.I. (2007). Predicting antibiotic resistance. Nat. Rev. Microbiol., 5: 958-965.

Miller R.W., Skinner J., Sulakvelidze A., Mathis G.F., Hof a cre C.L. (2010). Bacte- 
riophage therapy for control of necrotic enteritis of broiler chickens experimentally infected with Clostridium perfringens. Avian Dis., 54: 33-40.

M o e 11 e ri n g R.C. (2011). Discovering new antimicrobial agents. Int. J. Antimicrob. Agents, $37: 2-9$. M o h r K.I. (2016). History of antibiotics research. In: How to overcome the antibiotic crisis, M. Stadler, P. Dersch, eds. Cham, Springer International Publishing, pp. 237-272.

$\mathrm{N}$ a a f s M.A.B. (2018). The antimicrobial peptides: ready for clinical trials? Biomed. J. Sci. Tech. Res., 7: $6038-6042$.

N a m S., Choi Y., J ang S., Sh i m Y., H an G. (2016). Antimicrobial activity of propolis on different oral bacteria. Indian J. Sci. Technol., 9: 1-4.

N a m kung H., Li M., G ong J., Yu H., C ottrill M., d e L a n g e C.F.M. (2004). Impact of feeding blends of organic acids and herbal extracts on growth performance, gut microbiota and digestive function in newly weaned pigs. Can. J. Anim. Sci., 84: 697-704.

N is hi e M., N a g a o J.-I., S o n o m o to K. (2012). Antibacterial peptides "bacteriocins": an overview of their diverse characteristics and applications. Biocontrol. Sci., 17: 1-16.

Nobrega F.L., Costa A.R., Kluskens L.D., A zeredo J. (2015). Revisiting phage therapy: new applications for old resources. Trends Microbiol., 23: 185-191.

Olive ir a A.V., F erreira A.L., Nunes S., Dandlen S.A., Miguel M.D.G., F a le iro M.L. (2017). Antibacterial activity of propolis extracts from the south of Portugal. Pak. J. Pharm. Sci., 30.

Overdevest I., Willemsen I., Rijnsburger M., Eustace A., Xu L., Hawkey P., Heck M., Savelkoul P., Vandenbroucke-Grauls C., van der Zwaluw K., et al. (2011). Extended-spectrum $\beta$-lactamase genes of Escherichia coli in chicken meat and humans, The Netherlands. Emerg. Infect. Dis., 17: 1216-1222.

Pajor M., Worobo R.W., Milewski S., Szweda P. (2018). The antimicrobial potential of bacteria isolated from honey samples produced in the apiaries located in Pomeranian Voivodeship in Northern Poland. Int. J. Environ. Res. Public. Health, 15.

P e a c ock S.J., P aters on G.K. (2015). Mechanisms of methicillin resistance in Staphylococcus aureus. Annu. Rev. Biochem., 84: 577-601.

P e ters on E., K a u r P. (2018). Antibiotic resistance mechanisms in bacteria: relationships between resistance determinants of antibiotic producers, environmental bacteria, clinical pathogens. Front. Microbiol., 9.

P iris i A. (2000). Phage therapy - advantages over antibiotics? Lancet, 356: 1418.

Pouillard J. (2002). A forgotten discovery: doctor of medicine Ernest Duchesne's thesis (1874-1912). Hist. Sci. Medicales, 36: 11-20.

P r e s c ot t J.F. (2013). Beta-lactam antibiotics. In: Antimicrobial therapy in veterinary medicine. John Wiley \& Sons, Ltd, pp. 153-173.

Prystowsky J., Siddiqui F., Chosay J., Shinabarger D.L., Millichap J., Peters o n L.R., N o s k in G.A. (2001). Resistance to linezolid: characterization of mutations in rRNA and comparison of their occurrences in vancomycin-resistant enterococci. Antimicrob. Agents Chemother., 45: 2154-2156.

Przy byłe k I., K a r p ińs k i T.M. (2019). Antibacterial properties of propolis. Molecules, 24: 2047.

R a u t J.S., Ka r u p p y i 1 S.M. (2014). A status review on the medicinal properties of essential oils. Ind. Crops Prod., 62: 250-264.

R o c c a n ov a L., R a p p a P. (2000). Antibiotic rotation. Science, 287: 803.

S a g d i c O., Ek i c i L., O zturk I., Tek in a y T., P ol at B., Tas te mur B., B a y r a m O., S e n t u r k B. (2013). Cytotoxic and bioactive properties of different color tulip flowers and degradation kinetic of tulip flower anthocyanins. Food Chem. Toxicol., 58: 432-439.

S a t p a thy S., S e n S.K., P a t t a n a i k S., R a u t S. (2016). Review on bacterial biofilm: An universal cause of contamination. Biocatal. Agric. Biotechnol., 7: 56-66.

S chwarz S., Shen J., Kadle c K., Wang Y., Brenner Michael G., Feßler A.T., Ves t e r B. (2016). Lincosamides, streptogramins, phenicols, pleuromutilins: mode of action and mechanisms of resistance. Cold Spring Harb. Perspect. Med., 6.

$\mathrm{S}$ h a $\mathrm{m}$ a G. (2016). La Moisissure et la Bactérie: Deconstructing the fable of the discovery of penicillin by Ernest Duchesne. Endeavour, 40: 188-200.

S ing er A.C., Shaw H., Rhodes V., H a rt A. (2016). Review of antimicrobial resistance in the environment and its relevance to environmental regulators. Front. Microbiol., 7. 
S in g h B., S h a r m a R.A. (2015). Anti-inflammatory and antimicrobial properties of flavonoids from heliotropium subulatum exudate. Inflamm. Allergy Drug Targets, 14: 125-132.

S tefani S., Varald o P.E. (2003). Epidemiology of methicillin-resistant staphylococci in Europe. Clin. Microbiol. Infect., 9: 1179-1186.

Study of Omiganan 1\% gel in preventing catheter infections/colonization in patients with central venous catheters. ClinicalTrials.gov.

Szweda P., Gucwa K., Kurzyk E., Romanowska E., Dzierżanowska-Fangrat K., Zi e lińs k a - J u rek A., K u ś P.M., Milewski S. (2015). Essential oils, silver nanoparticles and propolis as alternative agents against fluconazole resistant Candida albicans, Candida glabrata and Candida krusei clinical isolates. Indian J. Microbiol., 55: 175-183.

Szweda P., Zalews ka M., Pilch J., Kot B., Milew ski S. (2018). Essential oils as potential anti-staphylococcal agents. Acta Vet. Beogr., 68: 95-107.

The European Union Summary Report on antimicrobial resistance in zoonotic and indicator bacteria from humans, animals and food in 2012 (2014). EFSA J., 12: 3590.

Trial of Iseganan in Prevention of Ventilator-Associated Pneumonia. ClinicalTrials.gov.

von Wintersdorff C.J.H., Penders J., van Niekerk J.M., Mills N.D., Majumder S., van Alphen L.B., S a velk oul P.H.M., Wolffs P.F.G. (2016). Dissemination of antimicrobial resistance in microbial ecosystems through horizontal gene transfer. Front. Microbiol., 7: 173.

Wa ihenya R.K., M tambo M.M.A., Nkwengulila G., Minga U.M. (2002). Efficacy of crude extract of Aloe secundiflora against Salmonella gallinarum in experimentally infected freerange chickens in Tanzania. J. Ethnopharmacol., 79: 317-323.

W a in w r i g h t M. (1985). Re-examination of some of John Tyndall's studies on microbial antagonism. Trans. Br. Mycol. Soc., 85: 526-529.

Wa k s m a n S.A. (1947). What is an antibiotic or an antibiotic substance? Mycologia, 39: 565-569.

Wang F.-H., Q i a o M., Chen Z., S u J.-Q., Z hu Y.-G. (2015). Antibiotic resistance genes in manure-amended soil and vegetables at harvest. J. Hazard. Mater., 299: 215-221.

Wa t t a m A.R., D a v is J.J., A s s a f R., B o is vert S., B rettin T., B u n C., C o n r a d N., D i e tri ch E.M., D is z T., G a b b a rd J.L., et al. (2017). Improvements to PATRIC, the all-bacterial Bioinformatics Database and Analysis Resource Center. Nucleic Acids Res., 45: D535-D542.

We s t o n R.J. (2000). The contribution of catalase and other natural products to the antibacterial activity of honey: a review. Food Chem., 71: 235-239.

W o c - C o lbur n L., F r a n c i s c o D.M.A. (2020). Multidrug resistance bacterial infection. In: Highly infectious diseases in critical care: a comprehensive clinical guide, J. Hidalgo, L. Woc-Colburn, eds. Cham: Springer International Publishing, pp. 139-146.

Wo $1 \mathrm{f}$ E.P., L e w is J.H. (1919) The effect of feeding yeast on antibody production. Int. J. Infect. Dis., 25: $311-314$.

Wo ln y - K oładka K., S i k o r a A., M a lin a D. (2018). Evaluation of silver nanoparticles toxicity to drug-resistant Escherichia coli strains isolated from municipal waste (in Polish). Infrastruktura Ekol. Teren. Wiej., 1: 7:23.

Wrigley S., Hayes M., Thom a R., Chrystal E.J.T., Ni chols on N. (2000). Biodiversity: new leads for the pharmaceutical and agrochemical industries. Royal Society of Chemistry.

Yoon K.-Y., Hoon Byeon J., Park J.-H., Hwang J. (2007). Susceptibility constants of Escherichia coli and Bacillus subtilis to silver and copper nanoparticles. Sci. Total Environ., 373 : $572-575$.

Zalewska M., Churey J.J., Worobo R.W., Milewski S., Szweda P. (2018). Isolation of bacteriocin-producing Staphylococcus spp. strains from human skin wounds, soft tissue infections and bovine mastitis. Pol. J. Microbiol., 67: 163-169.

Zankari E., Hasman H., Cosentino S., Vestergaard M., Ras mus sen S., Lund O., A a restrup F.M., Larsen M.V. (2012). Identification of acquired antimicrobial resistance genes. J. Antimicrob. Chemother., 67: 2640-2644.

Received: 18 XI 2019

Accepted: 9 IX 2020 